\title{
Avaliação de Processo na Implementação de Políticas Públicas: a Implantação do Sistema de Informação e Gestão de Recursos Humanos em Saúde (SIG-RHS) no Contexto das Reformas Setoriais
}

\begin{abstract}
A necessidade de se criar de instrumentos gerenciais para a área de recursos humanos em saúde induziu o desenvolvimento e a implantação do Sistema de Informação e Gestão de Recursos Humanos em Saúde (SIG-RHS). O artigo avalia o processo de implementação desse sistema nas Secretarias Estaduais e Municipais de Saúde de estados e municípios selecionados e apresenta a metodologia de avaliação de processo (de implementação), descrevendo as etapas e a construção de indicadores, além de discutir os resultados encontrados. Aponta ainda os limites e possibilidades para a utilização do SIG-RHS como instrumento de planejamento e gestão de recursos humanos em sistemas locais de saúde.
\end{abstract}

Palavras-chave: Recursos humanos em saúde pública; política de saúde; avaliação de políticas públicas; sistemas de informação. 


\section{Introdução}

O trabalho avalia a implantação de um programa informatizado para gestão de recursos humanos em saúde (SIG-RHS) ${ }^{3}$ no contexto de reforma do sistema de saúde. A metodologia utilizada foi a avaliação de processo. O estudo da avaliação do processo de implementação constitui uma subárea da avaliação de políticas públicas ${ }^{4}$. Consiste na avaliação da engenharia institucional e dos aspectos que traduzem o desenvolvimento de um programa ou projeto.

Cabe salientar que os estudos de avaliação das políticas públicas apresentam complexidade relacionada com diversos aspectos, o que tem dificultado sua utilização mais freqüente na prática institucional e acadêmica (Arretche, 1999). É consenso entre os pesquisadores da área que essas dificuldades podem estar relacionadas àquelas inerentes ao processo avaliado. Assim, podemos destacar:

- o reconhecimento de variáveis efetivamente relevantes;

- a pouca clareza sobre os reais objetivos a serem avaliados;

- a não-disponibilização de informação adequada;

- dificuldades de ordem técnica, decorrentes do estabelecimento de relações de causalidade entre programas e resultados.

A partir dessa complexidade, os estudos envolvem equipes e procedimentos qualificados dependentes de recursos de financiamento nem sempre disponíveis (Faria, 1999; Perez, 1999; Denis e Champagne, 1997; Viana, 1997).

No entanto, dentre as contribuições proporcionadas por esse tipo de pesquisa, pode-se qualificar o fornecimento de subsídios aos decisores para a correção das ações, pois não é restrita a diagnósticos, à capacidade de ampliar a efetividade da decisão relacionada aos programas públicos e à accountability desses programas, além de servir como elo integrador entre distintos componentes da política — o administrativo, o político e a comunidade (Perez, 1999). No Brasil essa ferramenta de avaliação tem sido desenvolvida e aplicada por pesquisadores em diversas áreas das políticas sociais e de saúde ${ }^{5}$.

O sistema de informação e gestão de recursos humanos em saúde (SIGRHS) começou a ser concebido no contexto das reformas do sistema de saúde, implementadas a partir de 1987, na Secretaria de Estado de Saúde do Estado do Rio de Janeiro (SES/RJ). A proposta de reforma, à época, preconizava a unificação da gestão local do sistema de saúde, independen- 
temente de esfera administrativa (Sistema Unificado e Descentralizado de Saúde - SUDS).

A partir da experiência desenvolvida na $\mathrm{SES} / \mathrm{RJ}^{6}$, o projeto que envolveu a concepção e disseminação do SIG-RHS foi desenvolvido, mais tarde, no Departamento de Planejamento e Administração em Saúde (DAPS) do Instituto de Medicina Social (IMS) da Universidade do Estado do Rio de Janeiro (UERJ).

O programa desenvolvido operava com arquivos do tipo Data Base File (DBF), em linguagem Clipper. Sua atualização e aprimoramento, com o desenvolvimento de sucessivas versões, foram feitos paralelamente à implantação do sistema, tendo como base as observações e críticas dos usuários. Mais ainda, poderia ser utilizado e disseminado nas instituições de saúde, dispensando qualificações específicas na área de informática, para manuseio. A partir de 1997, quando o projeto de pesquisa começou a ser realizado, foi desenvolvida a migração do sistema para ambiente Windows, em linguagem Delphi, mantendo-se ainda as características de relatórios fechados (SIG-RHS Versão 2.0 para Windows). A versão 3.0, em fase de conclusão, agrega modificações, como possibilidade de acúmulo histórico de dados relativos à vida funcional e relatórios abertos (disponibilizada em português, inglês e francês).

\section{Natureza da Investigação e Objetivos}

A avaliação da implantação do sistema de informação para a área de recursos humanos em saúde (SIG-RHS) aqui realizada foi de natureza qualitativa, voltada para avaliação de processo $^{7}$. O foco da investigação foi dirigido para os condicionantes institucionais do desempenho da implantação do SIG-RHS e do que poderia ser caracterizado como subsistemas, através dos quais foi realizada a implantação. Tentou-se identificar os fatores e situações que facilitam ou dificultam sua implementação, para alcançar os objetivos esperados pela introdução dessa tecnologia no arsenal de instrumentos passíveis de utilização para a gestão de recursos humanos em saúde.

Para a realização da pesquisa, foi utilizado o estudo de casos múltiplos, que, por suas características, é adequado à proposição do presente estudo e tem sido utilizado com freqüência no campo da pesquisa em administração pública.

Assinale-se que não foi objetivo do estudo discutir o funcionamento do programa e as características técnicas do software, mas sim a avaliação 
sistêmica da utilização de um instrumento (abordagem qualitativa de recursos humanos processados através de recursos de informática) e a potencial capacidade de mudança em processos de gestão de $\mathrm{RH}$, a partir da qualidade e da velocidade das informações obtidas. Desta forma, foram identificados alguns condicionantes da viabilização das políticas de saúde e suas relações com a política de recursos humanos implementadas para o setor, assim como se aferiram ainda prioridades para a apreensão de instrumentos gerenciais específicos, em situações que favoreçam ou dificultem seu desenvolvimento e incorporação institucional.

A implantação e utilização do SIG-RHS foi analisada através dos filtros dos indicadores de eficácia, eficiência técnica e eficiência social. Foram também avaliados alguns impactos esperados.

\subsection{Objetivo geral da investigação}

O objetivo geral do estudo foi avaliar a implantação de uma inovação para a área de gestão de recursos humanos em saúde - o SIG-RHS e a possibilidade de utilização das informações por ele geradas na formulação e implementação de políticas pertinentes para qualificação do processo de gestão do sistema de saúde.

\subsection{Objetivos específicos}

identificação dos diferentes tipos e graus de participação dos atores relevantes na implantação e utilização do SIG-RHS e sua intervenção na variação dos resultados esperados;

aferição da qualidade dos processos de implantação e dos fatores condicionantes para os resultados;

identificação dos limites e possibilidades para introdução de uma tecnologia com base em informações qualitativas na área de gestão de recursos humanos;

avaliação da satisfação dos gestores, pela utilização da informação na área de recursos humanos em saúde;

aferição da utilização da informação gerada pelo SIG-RHS por organizações de representação da área da saúde e outras.

\section{Concepção e Desenho Geral do Estudo}

De acordo com a natureza da investigação e o objetivo de avaliação de processo, as Secretarias de Saúde foram consideradas agentes 
implementadores. A equipe técnica do IMS foi excluída desta categoria e assumida como parte responsável pela disseminação operacional do siste$\mathrm{ma}^{8}$.

\subsection{Escolha dos casos}

A escolha dos locais para estudo contemplou quatro Secretarias Estaduais de Saúde e cinco Secretarias Municipais de Saúde, entre o universo que solicitou a implantação do SIG-RHS desde 1993.

Quando da realização do estudo, esses locais não necessariamente mantinham relações com a equipe responsável pelo desenvolvimento do projeto ${ }^{9}$ (a equipe poderia ou não estar acompanhando o desenvolvimento do processo). Optou-se, nesta escolha, por locais que obedecessem a critérios diversificados de localização geográfica e de regionalização, contingente de servidores a ser cadastrado e períodos de implantação não coincidentes que pudessem dar uma aproximação real das diversidades de ambientes institucionais para a implantação do SIG-RHS.

A escolha não envolveu qualificação prévia que pudesse estar relacionada com a implantação e utilização do sistema, na expectativa de que a diversidade de experiências pudesse contribuir para a identificação de similaridades e divergências no processo em estudo. Foram realizadas 15 entrevistas, com visita a nove locais.

\subsection{Hipóteses de trabalho}

A avaliação de processo apoiou-se em hipótese central e hipóteses específicas.

\subsubsection{Hipótese central}

As variações do desempenho (resultados) e do impacto da implantação do SIG-RHS estão correlacionadas à suficiência e à qualidade das operações dos sistemas de atividades, através dos quais se processa a implantação, assim como as prévias capacidades administrativas ou institucionais (state capabilities) das Secretarias de Saúde (denominadas agências implementadoras).

\subsubsection{Hipóteses especificas}

O desempenho, a eficiência social e os impactos institucional e social da implantação do SIG-RHS variam em função dos procedimentos e da adequação quantitativa e qualitativa dos recursos materiais, humanos e 
institucionais referentes aos subsistemas de atividades, através dos quais se processa a implantação. No processo em estudo, foram listados os seguintes subsistemas: adequação do locus de decisão e operacionalização; capacitação técnico-operacional; informações e divulgação do processo; avaliação e monitoramento; investimento e apoio logístico; e capacidades institucionais prévias.

As questões e proposições levantadas para a pesquisa foram ordenadas em três grupos: organização das Secretarias de Saúde e da gestão de recursos humanos; funcionamento do sistema de informação (SIG-RHS) e utilização da informação para apoio à formulação e implementação de política de recursos humanos para a saúde (capacidade de produzir insumos para modificar a relação recursos humanos/gestores/prestação de serviços de saúde).

A. Questões relativas à organização das Secretarias de Saúde e à gestão de recursos humanos:

A.1. centralização e descentralização do processo de decisão (instituição/ sistema);

A.2. processo de decisão da implantação do sistema e coordenação da operacionalização;

A.3. relações entre o sistema, os usuários e o grau de participação dos diferentes agentes no processo de decisão.

B. Questões relativas ao funcionamento do sistema de informação (SIGRHS):

B.1. recursos humanos necessários para implantação do sistema;

B.2. integração do sistema com os procedimentos utilizados na organização para a atualização dos dados;

B.3. utilização da informação: qualificação e periodicidade dos relatórios emitidos;

B.4. dificuldades e facilidades na implantação e utilização do sistema.

C. Questões relativas à utilização da informação para apoio à formulação e implementação de política de recursos para a saúde:

C.1. disseminação da informação e grau de participação dos gestores;

C.2. intervenção nos processos de planejamento e administração de recursos humanos (delimitação do universo);

C.3. capacidade de intervenção na estruturação da rede de serviços. 


\subsection{Variáveis e indicadores}

Entre os fatores que interferem na implantação e utilização do SIG-RHS, foram identificados, para efeito de análise, três grupos de variáveis:

\subsubsection{Variáveis independentes (indicadores de eficácia):}

Foram considerados variáveis independentes os fatores que operaram como condicionantes do desempenho da implantação do SIG-RHS. Os indicadores que captam essas variáveis são os indicadores de eficácia referidos aos conteúdos e à qualidade do processo desenvolvido para implantação do sistema.

As principais variáveis independentes são de natureza institucional e refletem as condições prévias das Secretarias de Saúde, dos agentes envolvidos na implementação do sistema e dos processos envolvidos na implantação do sistema de informação.

\subsubsection{Variáveis intervenientes}

Este grupo de variáveis contemplou fatores externos à atividade desenvolvida, que afetam os resultados esperados tanto positiva como negativamente, facilitando ou obstando a performance. No caso da implantação do SIG-RHS, podemos apontar:

- número de servidores a serem cadastrados;

- porte do local e área geográfica de abrangência;

- existência de outros sistemas desenvolvidos para recursos humanos no âmbito local de implantação do SIG-RHS;

- ausência de descentralização da gestão de recursos humanos por área de competência, no caso a descentralização para as Secretarias de Saúde, caracterizada em grande maioria pela gestão alocada nas Secretarias de Administração;

- centralização dos sistemas de processamento de dados e informação.

\subsubsection{Variáveis dependentes}

As variáveis dependentes foram referidas às medidas de desempenho, resultados e impacto da implantação do SIG-RHS que espelham o cumprimento das metas, os impactos sociais, entre outros. Estão delineadas nos indicadores de eficiência ou desempenho e de impacto, e se relacionam à eficiência técnica, à eficiência social e ao impacto da implantação do sistema. Para tanto, define-se eficiência como a capacidade de geração de um produto para o qual se está tecnicamente orientado (o conceito de eficiência 
técnica é similar ao de resultado e ao de desempenho) e a capacidade de satisfazer aos grupos de interesse envolvidos na sua execução, seja público-alvo, agentes implementadores, decisores etc. (stakeholders) ${ }^{10}$.

\subsubsection{Indicadores}

Indicadores de desempenho (eficiência técnica ou resultados): expressaram os resultados quantitativos obtidos na implantação do SIG-RHS em suas atividades-fins. Referem-se à cobertura e abrangência da coleta de dados, aos tempos e produtos relacionados com preenchimento dos cadastros traduzidos na atualização dos dados e na emissão de relatórios.

Desta forma:

a cobertura da implantação foi avaliada pelo cumprimento de metas relacionadas com o universo de servidores cadastrados;

- a qualidade dos cadastros foi medida através de mecanismos relacionados com as fontes para coleta de dados e o preenchimento completo dos campos discriminados no cadastro;

a produtividade foi aferida pelo período decorrido entre a coleta de dados e a emissão do primeiro relatório ${ }^{11}$;

- a regularidade da utilização do sistema avaliada pela sistematização da atualização de dados e emissão de relatórios.

\section{Indicadores de impacto:}

- a capacidade de indução a mudanças e inovações apreciada pela implantação do SIG-RHS. Esta capacidade pode se referir aos gerentes de recursos humanos, aos gestores do sistema de saúde e às organizações de saúde, com aprendizado, aperfeiçoamento e melhoria de processos institucionais favorecendo a realização de tarefas qualificadas e a procedimentos de integração gerencial entre setores das Secretarias de Saúde;

a capacidade de indução multiplicadora pela implantação do SIG-RHS, que pode ser traduzida no impacto sobre os processos de $\mathrm{RH}$, gerando novas iniciativas, estímulo à institucionalização ou à continuidade de experiências inovadoras.

Indicadores de eficiência social: resultaram da opinião e avaliação dos usuários do sistema (traduzidas por indicadores que se referem ao grau de satisfação com a implantação do sistema). De outro lado expressaram os indicadores de capital social, ou seja, a utilização das informações geradas 
pelo sistema por entidades de representação da área da saúde e fora dela, produzindo efeitos na capacidade organizativa e de mobilização dessas entidades (conselhos de saúde, associações profissionais etc.). As dimensões, variáveis e indicadores referidos estão resumidos no Quadro 1.

\section{Quadro 1. SIG-RHS. Dimensões e indicadores considerados}

\begin{tabular}{|c|c|}
\hline Dimensões da implantação do SIG-RHS & Indicadores \\
\hline Aspectos / processos & Indicadores de eficácia \\
\hline 口 Decisão da implantação & Nível; adequação \\
\hline Setor responsável & Nível; adequação \\
\hline 口 Capacitação técnico-operacional & Cobertura, abrangência; procedimentos \\
\hline Informações / divulgação & - Abrangência; adequação; publicização \\
\hline - Sistema de avaliação e monitoramento & Instrumentos; sistematização; adequação \\
\hline Investimento / apoio logístico & Suficiência; qualidade \\
\hline $\begin{array}{l}\text { Capacidades / ambientes institucionais } \\
\text { prévios das instituições implementadoras }\end{array}$ & 口 Suficiência; qualidade \\
\hline \multirow[t]{2}{*}{ Desempenho/resultados } & Indicadores de desempenho \\
\hline & $\begin{array}{l}\text { Coberturas; produção; tempo; } \\
\text { regularidade e produtividade na } \\
\text { atualização dos dados e emissão de } \\
\text { relatórios }\end{array}$ \\
\hline \multirow[t]{2}{*}{ Resultados indiretos e desdobramentos } & Indicadores de impacto \\
\hline & $\begin{array}{l}\text { Indução a mudanças / melhorias } \\
\text { institucionais; indução a inovações } \\
\text { nos processos de RH e na gestão do } \\
\text { sistema de saúde. }\end{array}$ \\
\hline \multirow[t]{3}{*}{ Apoios sociais } & Indicadores de eficiência social \\
\hline & $\begin{array}{l}\text { Uso das informações por instâncias de } \\
\text { representação e gestão da área da saúde } \\
\text { e outras }\end{array}$ \\
\hline & $\begin{array}{l}\text { Satisfação dos implementadores de } \\
\text { políticas na utilização das informações }\end{array}$ \\
\hline
\end{tabular}

Fonte: Avaliação da implantação do SIG-RHS (Pierantoni, 2000). 


\subsection{Coleta dos dados}

Foi realizada utilizando-se:

1. Coleta de dados secundários: documentos oficiais e publicações fornecidas pelas instituições ou solicitadas por ocasião das visitas, tais como plano de saúde, organograma da secretaria, capacidade instalada, convênios de gestão e boletins informativos.

2. Coleta de dados primários: dados obtidos em entrevistas realizadas nos locais escolhidos, obedecendo-se a roteiro estabelecido em questionário semi-estruturado ${ }^{12}$ previamente elaborado. O formato final do questionário foi definido a partir de pré-teste.

As entrevistas constituíram-se na principal fonte de dados, devido à escassez de regularidade das outras fontes.

A marcação das entrevistas foi precedida de contato com os locais selecionados e explicação dos objetivos da pesquisa com agendamento prévio. Os agentes escolhidos para essas entrevistas foram o gerente de recursos humanos (em exercício e o anterior, se possível), técnicos de outras áreas que participaram ou participam da implantação e desenvolvimento do sistema (área de informática e planejamento), obedecendo-se a critérios e disponibilidades locais. Desta forma, algumas entrevistas foram realizadas com a participação de mais de um técnico local.

As entrevistas foram realizadas com preenchimento de questionário semiestruturado e gravação de fitas para transcrição, e tiveram duração variável, não ultrapassando noventa minutos, dependendo da disponibilidade dos entrevistados. Foram posteriormente transcritas em sua totalidade para facilitar análise e consulta.

As visitas realizadas ao longo da pesquisa também serviram para atividades de consultoria aos locais selecionados para estudo, esclarecendo-se dúvidas tanto operacionais (de manuseio do sistema informatizado) quanto de utilização das informações coletadas e processadas. Em cada visita foi feito o registro de aspectos não contemplados nos questionários, a partir da observação livre do pesquisador.

\section{Observações sobre o Desenvolvimento do Estudo e suas Limita- ções}

As limitações da pesquisa, apontadas anteriormente, são inerentes à utilização da metodologia qualitativa. Estas limitações, entretanto, não invalidam o método, que apesar de não permitir universalizações, pode, ao estudar 
os processos envolvidos e suas relações, identificar singularidades e similaridades.

As limitações de observações colhidas por entrevistas também devem ser avaliadas reconhecendo-se as dificuldades que podem ser encontradas nesse tipo de pesquisa. Tais dificuldades podem ser estimadas a partir de relatos relacionados a eventos passados que por vezes não contaram com a participação dos entrevistados. Podem conter distorções condicionadas à interpretação de fatos passados ou ainda que o entrevistado não disponha da memória dos mesmos.

A transitoriedade de ações administrativas tem sido uma prática comum na administração pública, com freqüente alternância de poder e descontinuidade de ações. Desta forma, visando a recuperar informações e buscando uma fidelidade na reconstrução dos processos envolvidos com a implantação do SIG-RHS, houve necessidade de mais de uma entrevista em alguns locais.

Outro ponto que deve ser apontado se refere às limitações que podem ocorrer neste tipo de pesquisa e que estão relacionadas com aspectos envolvendo a subjetividade da pesquisadora na coleta, registro e análise das informações para o estudo. Estas questões se referem à participação direta da mesma em fases que envolveram a concepção, o desenvolvimento e implantação do sistema de informação.

As visitas e entrevistas realizadas nos locais selecionados permitiram o aprimoramento do software do SIG-RHS e a correção da metodologia de implantação. $\mathrm{O}$ acompanhamento realizado durante todo o período do processo de investigação permitiu a reformulação continuada do sistema, produzindo as versões posteriores e a migração para o ambiente Windows, a partir das experiências acumuladas. Outra consideração deve ser feita sobre a singularidade dos locais escolhidos para estudo: além de apresentarem situações específicas relacionadas, como contexto de abrangência da secretaria estudada (municipal ou estadual), sabe-se que o processo político de implementação das reformas setoriais não foi homogêneo, apresentando situações diversificadas e mesmo únicas em alguns casos.

\section{Critérios de Classificação dos Indicadores Utilizados}

A seguir apresentaremos os critérios selecionados para a construção de indicadores utilizados na avaliação da implantação do SIG-RHS nos estudos de casos selecionados. 
Quadro 2. SIG-RHS. Indicadores e respectivos critérios de classificação dos níveis de desempenho

\begin{tabular}{l|l|l|l|l}
\hline \multicolumn{2}{c}{ Desempenho } & \multicolumn{4}{c}{ Níveis } \\
\hline \multicolumn{1}{c|}{ Indicadores } & Atributos & Alto & Médio & Insuficiente \\
\hline $\begin{array}{l}\text { Cobertura da } \\
\text { implantação }\end{array}$ & $\begin{array}{l}\text { Quantitativo } \\
\text { de servidores } \\
\text { cadastrados }\end{array}$ & $\begin{array}{l}\text { Acima de } 90 \% \\
\text { de servidores } \\
\text { cadastrados }\end{array}$ & $\begin{array}{l}\text { Acima de } 70 \% \\
\text { de servidores } \\
\text { cadastrados }\end{array}$ & $\begin{array}{l}\text { Menos de } 70 \% \\
\text { de servidores } \\
\text { cadastrados }\end{array}$ \\
\hline $\begin{array}{l}\text { Qualidade do } \\
\text { cadastro }\end{array}$ & $\begin{array}{l}\text { Modo de } \\
\text { coleta de } \\
\text { dados } \\
\text { cadastrais }\end{array}$ & $\begin{array}{l}\text { Uso de fontes } \\
\text { primárias para } \\
\text { coleta de dados } \\
\text { e campos } \\
\text { completos }\end{array}$ & $\begin{array}{l}\text { Uso de fontes } \\
\text { secundárias e } \\
\text { revisão dos } \\
\text { cadastros mais } \\
\text { de 1 vez }\end{array}$ & $\begin{array}{l}\text { Cadastros } \\
\text { incompletos }\end{array}$ \\
\hline $\begin{array}{l}\text { Produtividade } \\
\text { da mplantação }\end{array}$ & $\begin{array}{l}\text { Emissão do } \\
\text { primeiro } \\
\text { relatório }\end{array}$ & $\begin{array}{l}\text { Menos de 3 } \\
\text { meses após a } \\
\text { coleta dos dados }\end{array}$ & $\begin{array}{l}\text { De 3 a 6 meses } \\
\text { após a coleta } \\
\text { dos dados }\end{array}$ & $\begin{array}{l}\text { Após 6 meses } \\
\text { ou não emitiu }\end{array}$ \\
\hline $\begin{array}{l}\text { Regularidade } \\
\text { da mplantação }\end{array}$ & $\begin{array}{l}\text { Atualização } \\
\text { de dados } \\
\text { cadastrais }\end{array}$ & $\begin{array}{l}\text { Dados } \\
\text { atualizados } \\
\text { rotineiramente }\end{array}$ & $\begin{array}{l}\text { Eventualmente } \\
\text { ou por demanda }\end{array}$ & $\begin{array}{l}\text { Não há } \\
\text { atualização dos } \\
\text { dados }\end{array}$ \\
\hline $\begin{array}{l}\text { Regularidade } \\
\text { da utilização }\end{array}$ & $\begin{array}{l}\text { Emissão de } \\
\text { relatórios }\end{array}$ & $\begin{array}{l}\text { Regularmente } \\
\text { até de 4 em 4 } \\
\text { meses ou por } \\
\text { solicitação }\end{array}$ & $\begin{array}{l}\text { Sem } \\
\text { regularidade } \\
\text { mas em período } \\
\text { não superior a 6 } \\
\text { meses }\end{array}$ & Não emite \\
\hline
\end{tabular}

Fonte: Avaliação da implantação do SIG-RHS (Pierantoni, 2000).

O quadro seguinte registra os indicadores de eficácia referidos aos sete macroprocessos identificados na implantação do SIG-RHS e selecionados para avaliação. 
Avaliação de Processo na Implementação de Políticas Públicas: a Implantação do...

Quadro 3. SIG-RHS. Critérios de classificação dos indicadores de eficácia

\begin{tabular}{|c|c|c|c|c|}
\hline \multirow[b]{2}{*}{ Indicador } & \multirow[b]{2}{*}{ Atributos } & \multicolumn{3}{|c|}{ Níveis de qualidade } \\
\hline & & Alta & Média & Insuficiente \\
\hline $\begin{array}{l}\text { Decisão da } \\
\text { implantação }\end{array}$ & $\begin{array}{l}\text { Nível de decisão da } \\
\text { implantação }\end{array}$ & $\begin{array}{l}\text { Secretário } \\
\mathrm{RH}\end{array}$ & $\mathrm{RH}$ & $\begin{array}{l}\text { Informática e } \\
\text { outros }\end{array}$ \\
\hline $\begin{array}{l}\text { Definição de } \\
\text { implantação / } \\
\text { operacionalização } \\
\text { do SIG-RHS }\end{array}$ & $\begin{array}{l}\text { Implantação e } \\
\text { operacionalização }\end{array}$ & $\begin{array}{l}\text { Mix profissional } \mathrm{RH} \text { e } \\
\text { Informática }\end{array}$ & $\mathrm{RH}$ & $\begin{array}{l}\text { Informática e } \\
\text { outros }\end{array}$ \\
\hline $\begin{array}{l}\text { Qualidade do } \\
\text { processo de } \\
\text { capacitação } \\
\text { Jtécnico } \\
\text {-operacional }\end{array}$ & $\begin{array}{l}\text { Treinamento da } \\
\text { equipe para coleta } \\
\text { de dados. } \\
\text { Acompanhamento } \\
\text { da coleta de dados }\end{array}$ & $\begin{array}{l}\text { Planejamento das etapas } \\
\text { para a coleta de dados. } \\
\text { Presença de um agente } \\
\text { implementador capacitado } \\
\text { para coleta de dados em } \\
\text { todos os locais. }\end{array}$ & $\begin{array}{l}\text { Presença eventual } \\
\text { de um agente } \\
\text { implementador } \\
\text { capacitado para a } \\
\text { coleta de dados. }\end{array}$ & $\begin{array}{l}\text { Coleta de dados } \\
\text { sem capacitação } \\
\text { prévia. }\end{array}$ \\
\hline $\begin{array}{l}\text { Qualidade do } \\
\text { processo de } \\
\text { divulgação / } \\
\text { informação para } \\
\text { os funcionários }\end{array}$ & $\begin{array}{l}\text { Sensibilização prévia } \\
\text { para a coleta de dados. } \\
\text { Uso de instrumentos } \\
\text { variados para } \\
\text { divulgação do } \\
\text { evento }\end{array}$ & $\begin{array}{l}\text { Material de divulgação nos } \\
\text { locais de coleta de dados. } \\
\text { Presença de um agente / } \\
\text { implementador para } \\
\text { esclarecimentos sobre o } \\
\text { processo. }\end{array}$ & $\begin{array}{l}\text { Material de } \\
\text { divulgação nos } \\
\text { locais de coleta de } \\
\text { dados. }\end{array}$ & $\begin{array}{l}\text { Ausência de } \\
\text { informações } \\
\text { sobre o processo. }\end{array}$ \\
\hline $\begin{array}{l}\text { Avaliação / } \\
\text { monitoramento }\end{array}$ & $\begin{array}{l}\text { Verificação da qualidade } \\
\text { de preenchimento dos } \\
\text { campos do cadastro. } \\
\text { Acompanhamento da } \\
\text { digitação, emissão de } \\
\text { relatórios e atualização } \\
\text { dos dados. }\end{array}$ & $\begin{array}{l}\text { Realização de pré- teste ou } \\
\text { validação dos dados do } \\
\text { cadastro por chefia superior } \\
\text { e todos os campos do } \\
\text { cadastro preenchidos e } \\
\text { atualização periódica dos } \\
\text { dados }\end{array}$ & $\begin{array}{l}\text { Todos os campos } \\
\text { do cadastro } \\
\text { preenchidos. }\end{array}$ & $\begin{array}{l}\text { Campos de } \\
\text { cadastro } \\
\text { incompletos. }\end{array}$ \\
\hline $\begin{array}{l}\text { Investimento / } \\
\text { apoio logístico }\end{array}$ & $\begin{array}{l}\text { Disponibilização de } \\
\text { recursos humanos. } \\
\text { Disponibilização de } \\
\text { recursos de informática. } \\
\text { Disponibilização de } \\
\text { recursos financeiros. }\end{array}$ & $\begin{array}{l}\text { Equipamento de informática } \\
\text { próprio; e técnicos } \\
\text { administrativos qualificados } \\
\text { para operar o sistema; e } \\
\text { suporte financeiro quando } \\
\text { necessário. }\end{array}$ & $\begin{array}{l}\text { Equipamento de } \\
\text { informática } \\
\text { compartilhado; e } \\
\text { técnicos } \\
\text { administrativos } \\
\text { qualificados. }\end{array}$ & $\begin{array}{l}\text { Ausência dos } \\
\text { itens anteriores. }\end{array}$ \\
\hline $\begin{array}{l}\text { Qualidade do } \\
\text { ambiente/ } \\
\text { capacidade } \\
\text { institucional } \\
\text { prévia }\end{array}$ & $\begin{array}{l}\text { Condições físicas } \\
\text { materiais e de recursos } \\
\text { humanos existentes. }\end{array}$ & $\begin{array}{l}\text { Gerência de RH com } \\
\text { especialização na área; } \\
\text { gerência de RH participante } \\
\text { das instâncias de decisão. } \\
\text { Gerência de Informática/ } \\
\text { Informação. Equipamento } \\
\text { de informática disponível. } \\
\text { Equipe técnica } \\
\text { administrativa qualificada. }\end{array}$ & $\begin{array}{l}\text { Gerência de } \mathrm{RH} \mathrm{e} \\
\text { pelo menos } 2 \text { das } \\
\text { condições } \\
\text { anteriores. }\end{array}$ & $\begin{array}{l}\text { Menos que } 3 \text { das } \\
\text { condições } \\
\text { anteriores. }\end{array}$ \\
\hline
\end{tabular}

RH: instância responsável por recursos humanos.

Fonte: Avaliação da implantação do SIG-RHS (Pierantoni, 2000). 
Os indicadores de eficiência social e impacto estão listados nos quadros a seguir:

Quadro 4 SIG-RHS. Dimensões da eficiência social

\begin{tabular}{l|l|l|l|l}
\hline \multicolumn{4}{|c}{ Eficiência social } \\
\hline \multirow{2}{*}{ Indicador } & Atributos & \multicolumn{3}{|c}{ Níveis } \\
\cline { 3 - 5 } $\begin{array}{l}\text { Avaliação do SIG- } \\
\text { RHS pelos } \\
\text { gestores de RH }\end{array}$ & $\begin{array}{l}\text { Utilização das informações nos } \\
\text { processos de RH. }\end{array}$ & Positiva & $\begin{array}{l}\text { Positiva } \\
\text { para pelo } \\
\text { menos } \\
\text { Utilização das informações nos } \\
\text { processos de gestão do sistema } \\
\text { de saúde. }\end{array}$ & Insuficiente \\
\hline & $\begin{array}{l}\text { Utilização das informações por } \\
\text { instâncias de representação e de } \\
\text { gestão da área da saúde. }\end{array}$ & & & \\
\end{tabular}

Fonte: Avaliação da implantação do SIG-RHS (Pierantoni, 2000).

Quadro 5 SIG-RHS. Resultados indiretos e desdobramentos. Indicadores de impacto

\begin{tabular}{|c|c|c|c|}
\hline \multicolumn{4}{|c|}{ Impacto } \\
\hline Indicador & Atributo & Sim & Não \\
\hline $\begin{array}{l}\text { Utilização das } \\
\text { informações } \\
\text { nos processos } \\
\text { de RH }\end{array}$ & $\begin{array}{l}\text { Melhorias nos } \\
\text { processos de } \\
\text { planejamento, } \\
\text { gestão e } \\
\text { qualificação de } \\
\text { RH }\end{array}$ & $\begin{array}{l}\text { A implantação do sistema influiu em } \\
\text { pelo menos três dos processos } \\
\text { apresentados: } \\
\text {. qualificação dos funcionários; } \\
\text {. planejamento de concursos; } \\
\text {. recomposição de equipes; } \\
\text {. educação continuada; } \\
\text {. elaboração de plano de cargos, } \\
\text { carreiras e salários; } \\
\text {. descentralização da gestão de RH. }\end{array}$ & $\begin{array}{l}\text { A implantação } \\
\text { do sistema não } \\
\text { alterou os } \\
\text { processos de } \\
\text { gestão de RH. }\end{array}$ \\
\hline $\begin{array}{l}\text { Utilização das } \\
\text { informações } \\
\text { em processos } \\
\text { de gestão do } \\
\text { sistema de } \\
\text { saúde local }\end{array}$ & $\begin{array}{l}\text { Indução a } \\
\text { inovações/ } \\
\text { reformulações }\end{array}$ & $\begin{array}{l}\text { A implantação do sistema: } \\
\text {. influiu na reestruturação dos serviços } \\
\text { de saúde; ou } \\
\text {. possibilitou a utilização das bases de } \\
\text { dados de recursos humanos com outras } \\
\text { bases de dados; ou } \\
\text {. permitiu a implantação de programas } \\
\text { de melhoria de desempenho. }\end{array}$ & $\begin{array}{l}\text { A implantação } \\
\text { do sistema não } \\
\text { alterou a gestão } \\
\text { do sistema de } \\
\text { saúde. }\end{array}$ \\
\hline
\end{tabular}

Fonte: Avaliação da implantação do SIG-RHS (Pierantoni, 2000). 


\section{Análise da Implantação do SIG-RHS: condições, processos e agen- tes}

Esta seção analisa as características de desempenho e processos da implantação do SIG-RHS, de acordo com as evidências coletadas nos casos estudados. É importante salientar que as observações coletadas se referem à ótica dos entrevistados, captando suas percepções, opiniões e avaliações. Mais ainda, foram ressaltados os aspectos relacionados com o objetivo final da implantação do SIG-RHS. No plano concreto, esses objetivos estavam direcionados para a utilização das informações geradas a partir do sistema, em situações que qualificassem os processos de gestão na área da saúde, a partir da ótica da gestão de recursos humanos.

Outro ponto a ser considerado se refere especificamente à utilização de meios informatizados e ao crescimento do conhecimento e multiplicação acelerada desses meios experimentada pela área nos últimos anos. Na pesquisa de campo realizada em 1997/1998, o ambiente DOS e a linguagem Clipper já não atendiam às necessidades de funcionamento do sistema em ambientes Windows. Embora este aspecto seja relevante nas observações realizadas, o foco de análise, como apontado anteriormente, não pretende discutir o desenvolvimento do software, mas a aplicabilidade das informações por ele geradas na área de recursos humanos em saúde.

A análise dos resultados encontrados será expressa nos desdobramentos utilizados para a avaliação, obedecendo aos critérios estabelecidos:

desempenho da implantação nos locais estudados;

características e qualidades dos processos de implantação, segundo a eficácia observada nos macroprocessos de implantação;

eficiência social segundo utilização das informações por instâncias gestoras ou de representação da área da saúde;

principais impactos referenciados aos processos de gestão de recursos humanos, à gestão do sistema local de saúde e outros processos;

relação entre os níveis de desempenho e os indicadores de eficácia observados;

relações entre desempenho, impacto e eficiência social.

Devemos ressaltar que algumas situações exemplares permearam espaços-limite dos parâmetros utilizados na avaliação. A partir da análise integrada dos casos, essas situações serão destacadas, assim como condicionantes facilitadores e obstáculos na implantação do SIG-RHS. 


\subsection{Níveis de desempenho dos locais estudados}

Para análise do desempenho da implantação do sistema de informação, foram escolhidos indicadores que sinalizassem a possibilidade de utilização do SIG-RHS em sua plena capacidade. Assim, os indicadores selecionados referiam-se à cobertura de implantação, à qualidade dos cadastros, à produtividade da implantação expressa pela emissão do primeiro relatório após a coleta dos dados cadastrais e à regularidade de utilização do sistema, através de atualização sistemática de dados e emissão de relatórios.

Tendo submetido a tais critérios os locais estudados, encontramos a seguinte classificação:

Quadro 6. SIG-RHS. Classificação dos locais por níveis de desempenho

\begin{tabular}{c|c|c}
\hline \multicolumn{3}{|c}{ Níveis de Desempenho } \\
\hline Alto & Médio & Insuficiente \\
\hline $\begin{array}{c}\text { Angra dos Reis } \\
\text { BH } \\
\text { Montes Claros } \\
\text { Espírito Santo }\end{array}$ & Campinas & $\begin{array}{c}\text { Contagem } \\
\text { Pernambuco } \\
\text { Alagoas }\end{array}$ \\
\hline
\end{tabular}

Fonte: Avaliação da implantação do SIG-RHS (Pierantoni, 2000).

As situações extremas observadas referem-se aos municípios de Belo Horizonte, Angra dos Reis, Montes Claros e ao estado do Espírito Santo, contrapondo-se ao município de Contagem e ao estado do Rio Grande do Norte. Em situações intermediárias, encontramos o município de Campinas, e os estados de Alagoas e Pernambuco. A partir destes resultados, podemos destacar algumas situações especiais.

Apesar das diferenças entre os locais estudados, os municípios de Angra dos Reis, Belo Horizonte, Montes Claros e o estado do Espírito Santo cadastraram $100 \%$ dos funcionários na área de abrangência, à época do estudo. O estado do Espírito Santo possuía 90\% de servidores cadastrados (e posteriormente completou o cadastro); os não-cadastrados corresponderam a servidores afastados e licenciados.

O quantitativo de servidores a serem cadastrados e abrangência geográfica do processo que poderiam antepor dificuldades para a coleta dos dados demonstraram não influir no processo. Este parece depender de condições 
de adaptação à realidade e complexidade locais, assumidas tanto no planejamento quanto pelo desenvolvimento adequado dos processos envolvidos na implantação.

O caso de Belo Horizonte merece destaque, pois a implantação foi realizada após uma tentativa frustrada em período anterior. A primeira tentativa teve início a partir da coleta de dados secundários originados de um processo de cadastramento anterior realizado pelo centro de processamento de dados local (PRODABEL). Foi realizada a transposição dos dados do cadastro existente, que se revelou inconsistente com os dados reais, após teste por amostragem. Em 1996, o SIG-RHS foi o sistema de informação de recursos humanos escolhido para a implementação do Sistema de Avaliação de Desempenho (SADE). Esse sistema seria implantado para utilização em unidades de saúde que obtiveram aprovação dos seus planos de metas e indicadores dos projetos de saúde. Previa, ainda, a cada avaliação quadrimestral, o pagamento de uma gratificação prevista em lei. Os dados de cadastro foram obtidos a partir de informações coletadas junto aos servidores e suas unidades de serviço, de maneira descentralizada. O primeiro relatório foi emitido em período inferior a três meses.

Este fato ressalta a importância de se realizar a coleta dos dados a partir de fontes primárias, no sentido de minimizar distorções e incorreções no preenchimento dos cadastros. Neste particular, devemos ressaltar que todos os locais estudados apontaram dificuldades de diversas ordens no preenchimento dos cadastros que se relacionavam, primordialmente, com a resistência ao fornecimento de dados.

A prática administrativa sedimentada em procedimentos censitários, sem objetivos definidos e sem retorno para o público-alvo, provocou reações de descrédito relacionadas à utilização da informação. Mais ainda, com a instalação da reforma administrativa, que alterava significativamente mecanismos de incorporações e vantagens pessoais, detectava acumulações não previstas na legislação vigente e alterava períodos de aposentadoria por tempo de serviço. Entre outras coisas, o aparecimento de um novo "cadastro" predizia mais um mecanismo de "punição".

Com o objetivo de diminuir os erros em dados cadastrais, a validação por chefias imediatamente superiores mostrou-se um procedimento útil, particularmente em unidades e locais de menor porte, como observado em Angra do Reis e nas coletas descentralizadas (Pernambuco e Espírito Santo).

O município de Contagem, apesar de possuir 1.060 funcionários e cadastrar $100 \%$ deles, não conseguiu obter dados para o preenchimento adequado 
de todos os campos. Entre os motivos descritos estava a "enorme rotatividade e evasão de funcionários da Secretaria de Saúde, pela proximidade com outros municípios, especialmente Belo Horizonte, que favorece a migração de funcionários dependendo das condições de trabalho". Optou pelo preenchimento incompleto dos cadastros, o que permitia operar os relatórios nominais. Este município foi o único local a não completar os cadastros.

No estado do Rio Grande Norte, a implantação do SIG-RHS atingiu pouco mais de $50 \%$ dos funcionários. Sua implantação foi regionalizada e, à época do estudo, a área correspondente à $1^{\mathrm{a}}$ Região não havia completado a etapa de coleta de dados. A responsável pela área de recursos humanos estava há pouco tempo na função e questionava o SIG-RHS implementado na gestão anterior. $\mathrm{O}$ processo de implantação estava paralisado.

Nas situações intermediárias, observadas em Campinas e nos estados de Pernambuco e Alagoas, o quantitativo de servidores cadastrados foi superior a $80 \%$. Os demais indicadores de desempenho tiveram comportamentos variados. Campinas emitiu o primeiro relatório, manteve a atualização dos dados e emissão de relatórios nos períodos aprazados. As dificuldades para completar a coleta dos dados foram relacionadas com a mudança da gestão municipal.

No estado de Pernambuco, a implantação do SIG-RHS foi feita de forma escalonada e regionalizada, para atender aos interesses demandados a partir das distâncias geográficas e da distribuição desigual de servidores em locais e unidades de saúde com grande concentração e desconcentração de funcionários (capital x interior). Desta forma, em locais com menor contigente de funcionários a serem cadastrados, as barreiras geográficas funcionaram como obstáculos para a coleta satisfatória de dados e atualizações de cadastros, principalmente.

Avaliamos que, agregando-se locais de alto e médio desempenhos, estes representaram sete dos nove locais estudados. Apesar das diferenças entre os locais de implantação, representadas pelo porte da secretaria e das unidades de saúde, assim como pelas distâncias geográficas, estes fatores não se mostraram como obstáculos para uma coleta de dados e preenchimento de cadastro que possibilitassem o funcionamento adequado do sistema. As diferenças observadas no desempenho dos locais estudados merecem ser analisadas pelo filtro do processo de implantação.

Em que processo desenvolvido as diferenças ou similaridades podem ser detectadas? Qual a correlação entre o desempenho observado e o impacto da implantação nos processos de RH e de gestão do sistema de saúde? 
Pode-se considerar alguma eficiência social a partir da implantação do SIGRHS?

\subsection{As dimensões da implantação do SIG-RHS}

A caracterização e avaliação dos processos de implantação do SIG-RHS - relacionadas com a decisão da implantação do sistema e o locus de implantação e operacionalização, com a qualidade dos processos de capacitação técnico-operacional, de divulgação para os funcionários, de monitoramento e avaliação da implantação, do investimento e apoio logístico dispensado e da capacidade institucional prévia - indicam os graus de eficácia dos locais estudados. A partir do filtro desses indicadores, podemos estimar o grau de influência de tais processos nos níveis de desempenho observados.

A distribuição dos locais por níveis de desempenho e graus de eficácia dos processos analisados encontra-se resumida no Quadro 7.

Os processos que podem ser relacionados com o alto desempenho entre os indicadores escolhidos estão relacionados com a operacionalização do sistema pelo setor de RH e informática, e pelo monitoramento exercido ao longo do processo. Em seguida, podemos agrupar a qualidade do processo de informação e divulgação, o investimento realizado no processo de implantação e a capacidade institucional prévia. A decisão da implantação e a qualidade do processo de capacitação técnico-operacional demonstraram distribuições aleatórias, quando correlacionadas com o grau de desempenho nos locais estudados.

A reorganização do sistema de saúde local experimentada nos diferentes locais estudados foi o fator decisivo para as demandas de implantação do SIG-RHS. Encontramos nos casos estudados situações de magnitude extrema. SES com grande número de funcionários, situações de exceção relacionadas com vínculos, carga horária, lotação, desvios de função, ausência de reposição dos cargos vacantes, entre outras, impunham a necessidade de informações sistematizadas sobre a situação atual dos RH.

Em outro extremo, estavam as SMS com quadro menor de funcionários, realização recente de concursos e necessidade de informações que qualificassem o processo de gerência de recursos humanos, em paralelo com a organização e autonomia de gestão do sistema de saúde em curso.

As duas situações demandaram necessidades distintas para a informação sobre os RHS: uma relacionada com as dificuldades de organização da capacidade de RH existente (SES); e outra, de acompanhamento de situa- 
Quadro 7. SIG-RHS. Distribuição dos locais por níveis de eficácia e desempenho

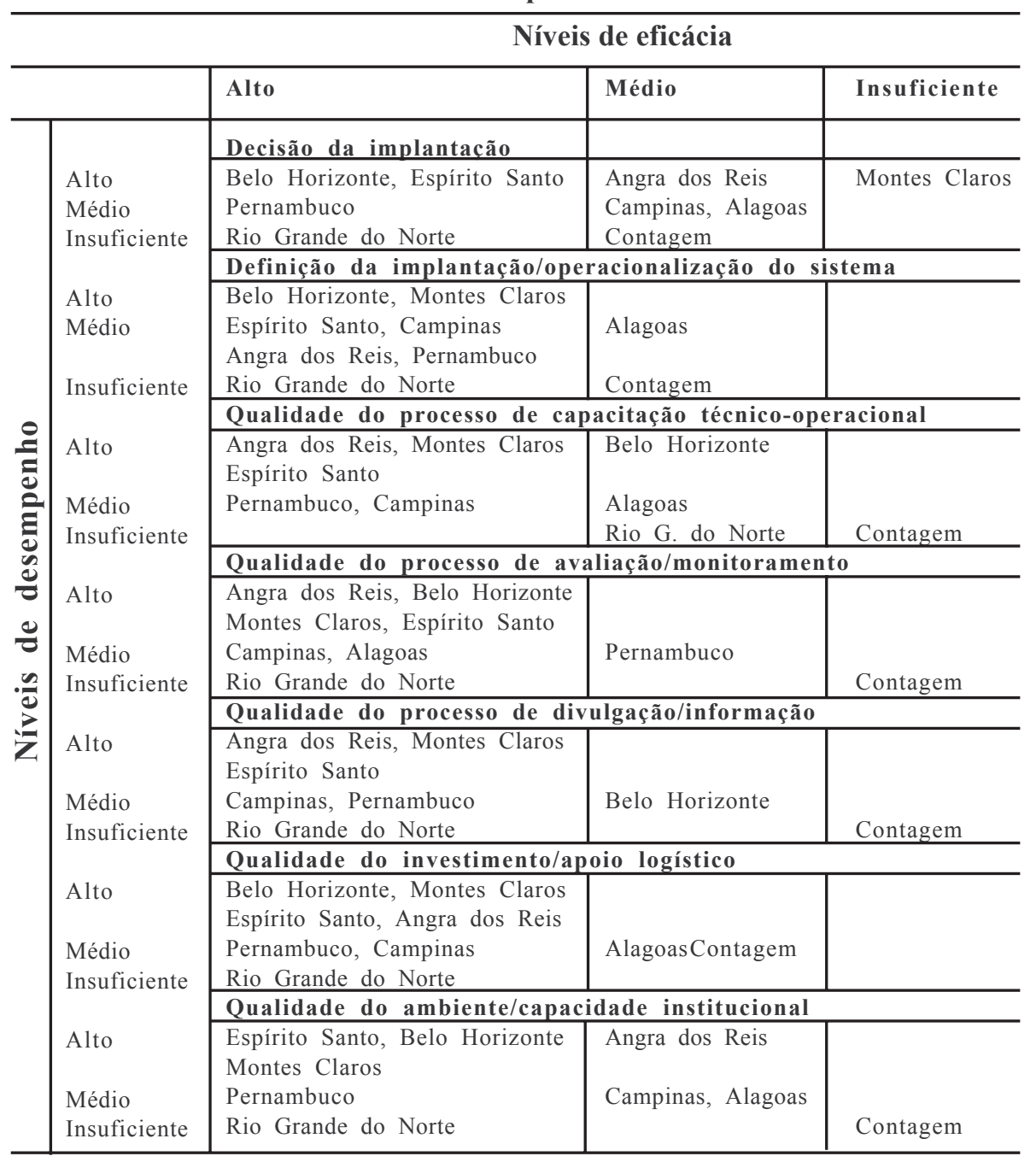

Fonte: Avaliação da implantação do SIG-RHS (Pierantoni, 2000) 
ções recentes, articulando ações de saúde e recursos humanos em processos de desenvolvimento e avaliação da reforma do sistema de saúde (SMS).

A participação de instâncias de decisão superior, como o Secretário de Saúde, na implantação do sistema, embora tenha sido decisiva em alguns casos, como a SES do Espírito Santo e na SMS de Belo Horizonte, mostrouse irrelevante em outros, como no caso da SES do Rio Grande do Norte.

A gerência de RH foi o locus operacional em todos os locais estudados e, aliada ao suporte técnico qualificado da área de informática, determinou condições de alto e médio desempenhos, com exceção da SES do Rio Grande do Norte. Aqui merecem registro dois fatos: a informatização das secretarias como instrumento de desenvolvimento institucional e a qualificação dos gerentes de RH.

Cada vez mais se correlaciona "modernidade" com tecnologia e gestão. O desenvolvimento da informática e sua presença na sociedade moderna vêm disponibilizando recursos para um número crescente de pessoas e organizações. A informação passa a ser objeto de interesse não só disciplinar, mas também de interesse prático imediato, tornando-se valor de produção, responsável por ações técnicas e administrativas (Carvalho, 1998).

Dos locais analisados, apenas Contagem e Campinas não apresentavam uma gerência com experiência na área de RH. A gerente de RH da SES do Espírito Santo era docente da Universidade Federal do Espírito Santo, onde havia exercido anteriormente o cargo de Sub-reitora de Extensão. Essas observações apontam para um quadro de profissionalização da gerência da área de RH nos locais estudados. A fonte de qualificação apontada foi o Curso de Especialização em RH da OPAS/MS.

A qualidade do processo de capacitação técnico-operacional foi realizada em todos os locais, adaptando-se às diferenças regionais. Em locais de pequeno porte, como por exemplo Angra dos Reis, a implantação foi realizada centralizadamente, envolvendo dois funcionários capacitados para tal finalidade.

A SES do Espírito Santo utilizou estratégias descentralizadas para a implantação do SIG-RHS. Promoveu uma sensibilização de diretores de unidades por região do estado e capacitou pessoal técnico auxiliar para acompanhamento local da coleta de dados e preenchimento dos cadastros.

Na SMS de Belo Horizonte não foi feita capacitação local prévia mas o processo de coleta de dados era supervisionado por um técnico habilitado (o depoimento fala da carência de treinamento). Neste caso, os processos relacionados com a avaliação e o acompanhamento superaram as dificulda- 
des determinadas por ausência de equipe técnica qualificada. Os erros detectados na coleta e preenchimento dos cadastros, em sua maioria, puderam ser corrigidos pelo acompanhamento sistemático da digitação de dados e atualização dos cadastros.

As dificuldades deste indicador, observadas na SES de Pernambuco, relacionavam-se com a atualização de dados, devido às distâncias geográficas (a comunicação através da rede de computadores estava sendo discutida mas dependia de uma melhor qualidade do sistema de telefonia do estado).

Com relação a estes dois indicadores, cabe uma observação. A orientação da equipe técnica do IMS/UERJ enfatizava a importância dessas etapas para a qualidade dos dados coletados e da informação a ser processada. Assim, houve uma padronização, executada de acordo com as orientações recebidas e adaptada para as disponibilidades locais.

O mesmo pode ser observado com respeito aos processos de informação e divulgação da implantação do SIG-RHS. Todos os locais estudados fizeram cartazes, folders, palestras, divulgação local por rádio etc., na dependência dos recursos disponíveis e da abrangência da área de implantação. Seguramente, tais procedimentos contribuíram para minimizar as resistências ao fornecimento dos dados, que, como foi destacado anteriormente, operou como uma das dificuldades para o preenchimento dos campos de cadastro.

A observação comparada dos indicadores de capacidade institucional prévia e investimento e apoio logístico permite inferir que, independentemente das capacidades institucionais prévias, o investimento realizado nas SMS influiu positivamente para o êxito alcançado na implantação do SIG-RHS. Com relação às SES, à exceção do Espírito Santo (que já possuía alta capacidade institucional e investiu no processo de implantação), o comportamento desses indicadores demonstrou resultados aleatórios.

A avaliação individualizada dos casos permite detectar especificidades e condicionantes locais, relativos ao processo de reforma em curso, que podem ter colaborado para o êxito ou dificuldade de realização da implantação.

\subsection{Situação exemplar}

No município de Angra dos Reis, por exemplo, não houve participação do secretário na decisão da implantação. A solicitação da implantação partiu da direção de RH da SMS e contou com a colaboração do setor de informática da Prefeitura. A SMS experimentou intenso processo de organização a partir de 1989. Anteriormente, possuía um quadro de pessoal restrito a 
poucas categorias profissionais (cerca de 100 servidores). Realizou concursos e expandiu seu quadro para 660 servidores. O crescimento do número de servidores foi fator decisivo para as demandas de implantação do SIGRHS. A municipalização agregou os funcionários do INAMPS e da Secretaria de Saúde do Estado do Rio de Janeiro, atingindo um quantitativo de 846 servidores cadastrados. Os recursos necessários para autonomia do setor de RH da SMS foram disponibilizados ao longo do processo, enfrentando resistências da área de administração da prefeitura. Vem utilizando o sistema, desde a implantação, com atualização do software SIG-RHS (versão 2.0).

\subsection{Eficiência social: breves comentários}

As medidas para este indicador foram estimadas inicialmente em duas ordens: a opinião dos gestores de RH sobre o sistema e a utilização da informação em RH num conjunto de ações que extrapolassem condições únicas de gestão de RHS e do sistema de saúde, de um lado; e a utilização dessas informações por outras instâncias de representação e gestão na área da saúde, de outro. Essas instâncias estariam contempladas em entidades de representação profissional e conselhos de saúde.

Entretanto, as avaliações obtidas alcançaram apenas a opinião dos gestores sobre a utilização das informações. A utilização das informações pelas outras instâncias, quer de representação profissional quer de gestão (como os conselhos de saúde), foi sinalizada pelos gestores de RH, não sendo possível classificá-la no foco das instituições que as solicitaram.

Optamos pela escolha da avaliação deste indicador a partir da opinião dos gestores (Quadro 8).

Quadro 8. SIG-RHS. Classificação dos locais por níveis de eficiência social

\begin{tabular}{|c|c|c|}
\hline \multicolumn{3}{|c|}{ Níveis de eficiência social } \\
\hline Indicador & Alto & Médio \\
\hline $\begin{array}{l}\text { Avaliação da implantação do } \\
\text { SIG-RHS pelos gestores de } \\
\text { RH }\end{array}$ & $\begin{array}{l}\text { BH } \\
\text { Angra dos Reis } \\
\text { Montes Claros } \\
\text { Espírito Santo } \\
\text { Alagoas }\end{array}$ & $\begin{array}{l}\text { Contagem } \\
\text { Campinas } \\
\text { Rio Grande do Norte } \\
\text { Pernambuco }\end{array}$ \\
\hline
\end{tabular}

Fonte: Avaliação da implantação do SIG-RHS (Pierantoni, 2000). 
A eficiência social foi considerada elevada em três SMS que emitiram opinião satisfatória sobre a utilização do sistema em demandas internas e externas. Entre as externas, foi sinalizado o uso da informação, desde a atualização de dados cadastrais de conselhos profissionais e sindicatos (Belo Horizonte e Angra dos Reis), ao instrumento facilitador para a construção de aprovação de plano de saúde nas instâncias colegiadas dos Conselhos Municipais de Saúde (Belo Horizonte, Angra dos Reis e Montes Claros).

A utilização da informação fora do âmbito administrativo - como, por exemplo, por entidades de representação profissional - levantou questões importantes relativas aos aspectos éticos da divulgação da informação. A informação tem sido valorizada como instrumento para o desenvolvimento das organizações. Sua divulgação é fator de aprimoramento das instituições na direção do fortalecimento de processos democráticos. $\mathrm{O}$ equilíbrio entre o acesso às informações e sua utilização deve ser mediado por condições éticas que preservem as instituições e as pessoas, não as transformando em objetos manipuláveis.

6.5. Resultados indiretos e desdobramentos: indicadores de impacto O impacto institucional da implantação do SIG-RHS foi avaliado segundo critérios de utilização da informação processada pelo sistema, em dois níveis: - utilização da informação em processos de RH, relacionados de forma aleatória mas que contemplassem as questões freqüentes na gestão de RH. Assim, foram listados processos de utilização da informação para qualificação de funcionários ${ }^{13}$, planejamento de concursos, recomposição de equipes, educação continuada ${ }^{14}$ e elaboração de planos de cargos e carreiras. A descentralização da gestão de recursos humanos foi incluída neste grupo a partir de demandas da municipalização, por um lado, e de autonomia de gestão para unidades de serviço de saúde, particularmente unidades hospitalares de grande porte, por outro;

- utilização da informação em processos de gestão do sistema de saúde, relacionados com atividades integradas de planejamento e execução, como reestruturação da rede de serviços, utilização da base de dados com outros sistemas (relacionados com a vigilância epidemiológica, estatísticas vitais, administração de serviços, por exemplo) e para implantação de processos de avaliação de desempenho. Mais uma vez, essas opções são resultado de demandas e atividades executadas 
nas Secretarias de Saúde em que as informações sobre RH apresentam limites de confiabilidade variável ou não existem.

Obviamente não era nossa expectativa uma homogeneidade na qualificação e desenvolvimento desses processos nas secretarias estudadas. As observações coletadas referem-se a capacidades e necessidades de cada local estudado e às diferentes situações determinantes da direcionalidade da utilização de informações sobre RHS. Porém, os resultados encontrados na avaliação desses indicadores merecem ser observados.

Quadro 9. SIG-RHS. Distribuição dos locais por indicadores de impacto

\begin{tabular}{l|l|l}
\hline Locais/ Indicadores & $\begin{array}{l}\text { Utilização das } \\
\text { informações em } \\
\text { processos de RH }\end{array}$ & $\begin{array}{l}\text { Utilização das } \\
\text { informações em } \\
\text { processos de gestão do } \\
\text { sistema de saúde local }\end{array}$ \\
\hline Belo Horizonte & SIM & SIM \\
Contagem & SIM & SIM \\
Angra dos Reis & SIM & SIM \\
Campinas & SIM & SIM \\
Montes Claros & SIM & SIM \\
Espírito Santo & SIM & SIM \\
Rio Grande do Norte & SIM & SIM \\
Pernambuco & SIM & NÃO \\
Alagoas & SIM & SIM-RHS(Pign \\
\hline
\end{tabular}

Fonte: Avaliação da implantação do SIG-RHS (Pierantoni, 2000).

Independentemente do desempenho observado na implantação do SIGRHS, o impacto da implantação foi positivo em todos os locais estudados: a informação gerada pelo sistema foi utilizada em processos relacionados com RH. Este fato chama atenção especialmente na SMS de Contagem e na SES do Rio Grande do Norte. O indicador de impacto aponta para a utilização da informação em RH, mesmo em condições adversas relacionadas com a qualidade dos processos institucionais envolvidos.

O município de Contagem logrou cadastrar quase $100 \%$ dos funcionários em sua esfera administrativa e abandonou o preenchimento completo dos cadastros por falta de equipamento de informática (o equipamento atual estava em uso há três meses) e técnicos habilitados para digitação. Entretanto, as informações cadastrais presentes no sistema permitiram a emissão 
de relatórios nominais. Desta forma, mesmo com dados incompletos, as informações geradas foram maximamente utilizadas em ações de remanejamento, planejamento de educação continuada e de qualificação de funcionários, realizadas em cooperação com a Escola de Saúde de Minas Gerais (ESMIG). Auxiliaram ainda na realização de concurso para especialidades médicas e de enfermagem. Mais ainda, mostram-se úteis em processo relativos à gestão do sistema de saúde, determinando condições de dimensionamento da rede de serviços de saúde (por exemplo, fechamento de unidade de saúde ociosa).

Em realidade, o sistema foi utilizado como cadastro, emitindo listagens nominais que possibilitaram a realização desse processo. O quantitativo de funcionários (1.060, sendo 700 da própria SMS e o restante do INAMPS e SES de Minas Gerais) também facilitou a utilização da informação, mesmo sem o auxílio de relatórios estatísticos.

O processo de implantação desenvolvido na SES do Rio Grande do Norte cadastrou pouco mais de $50 \%$ dos funcionários da rede de serviços de saúde. Foi implementado por regiões, e mesmo representando uma situação de exceção na relação desempenho/indicadores de eficácia, utilizou as informações processadas para a elaboração de um PCCS, de treinamentos e de remanejamentos nas unidades de saúde de regiões cadastradas. A utilização das informações em processos mais gerais de reorientação do sistema de saúde ficou fortemente prejudicada pelo baixo universo atingido pela implantação do SIG-RHS.

Essas observações, aliadas à utilização das informações produzidas pelo sistema em locais com médio e alto desempenhos na implantação, apontam para a interferência de outros fatores na implantação e institucionalização de processos de gestão. Entre os aspectos gerais ressaltados nas entrevistas, aparecem os relativos à concepção do software.

Em sua concepção inicial, os relatórios e cruzamentos de dados eram fechados, não permitindo escolha de outras variáveis e outros cruzamentos. Outro ponto considerado importante era a incapacidade do sistema em manter o registro histórico dos episódios relacionados com "vida" institucional dos funcionários. Tais observações fortaleceram a necessidade de modificações na lógica do software e foram incorporadas à versão atualizada (SIG-RHS 3.0)

Em casos singulares, a interferência de fatores locais determinou o direcionamento da utilização do SIG-RHS. No caso da SMS de Contagem e na SES do Rio Grande do Norte, destaca-se a descontinuidade da gestão, 
com mudanças de governo entre a decisão da implantação e o alcance dos objetivos finalísticos da decisão.

Não há dúvidas com relação à necessidade das informações e da pertinência da informatização para agilidade e disponibilização de fontes que qualifiquem as decisões em processos relacionados com RH. Podemos inferir que a baixa institucionalidade do processo pode representar importante fator limitante, condicionando dificuldades que podem ser ordenadas em categorias relacionadas com a baixa capacidade institucional prévia (Contagem) e a transitoriedade de ações administrativas determinadas por mudanças sucessivas de gestão (Rio Grande do Norte).

Consulta telefônica aos locais estudados apontou que, independentemente de limitações operacionais relacionadas com o software e adaptações necessárias experimentadas com a velocidade de crescimento e incorporação da tecnologia informacional no cotidiano das organizações e das pessoas, o SIG-RHS vem sendo utilizado nos locais estudados, à exceção de Contagem, do Rio Grande do Norte e do Espírito Santo. Este merece observação cuidadosa.

Embora apresentando alto desempenho e qualificação dos indicadores de eficácia, enfrentou dificuldades administrativas não exclusivas da Saúde, mas decorrentes de crise fiscal intensa, que demandou períodos de greves prolongadas de todo o quadro funcional da esfera estadual, inclusive dos técnicos de nível central. $\mathrm{O}$ desgaste experimentado pelos gestores, particularmente de RH, pode ser expresso no questionamento da "pertinência de informações e manutenção do sistema em um quadro de ausência de perspectivas de regularização e melhoria de condições salariais" (entrevista, SES do Espírito Santo).

Desta forma, inferimos que situações de desempenho, eficácia e impacto na implantação de um sistema de informação para gestão de RH não apresentam relações lineares. A gestão de RH e do sistema local de saúde está condicionada à manutenção de condições relativas à qualidade e investimento na capacidade institucional (Contagem), à manutenção institucionalizada de processos considerados inovadores (Rio Grande do Norte) e à preservação mínima de condições gerais de satisfação com a administração pública (Espírito Santo).

\subsection{Casos exemplares}

Extraímos alguns relatos das entrevistas que ilustram situações de facilidades e dificuldades observadas na implantação do SIG-RHS. 


\section{Angra dos Reis:}

“(...) nós da Saúde somos mais precários. Tudo nosso é emprestado, é dos outros. A gente com pouco faz muito e eles com muito não fazem nada (...). Todo mundo tem que ter acesso às informações, todo mundo quem? Não só as pessoas qualificadas, aí eu pergunto? Quem são as pessoas qualificadas?(...) O dado é público, realmente o dado é público (...)"

\section{Belo Horizonte:}

“(...) um dos grandes problemas no início foi que não havia infra-estrutura, nem em termos de equipamento nem em termos de recursos humanos, então você tinha a decisão política pela implantação mas não tinha a infra-estrutura (...) foi preciso que toda essa infra-estrutura fosse montada (...). O que tentamos o tempo inteiro é fazer a mesa de negociação, não conseguimos o PCCS porque a Secretaria de Administração colocou muito problema, colocou que a Saúde já era o precedente para tudo, que a Saúde já fazia tudo diferente. Por exemplo, toda a parte de administração de pessoal da Saúde nós tomamos para nós, então a administração não fazia mais nada em relação à Saúde, e nas outras secretarias é ela que faz os treinamentos, tudo, né? Então eles acharam que a gente estava grande demais, e que essa proposta, apesar de ser com a Prefeitura do PT, aberta a essa discussão, tinha problemas jurídicos e, enfim, eles colocaram uma série de empecilhos (...) Em cada distrito um responsável por RH e um administrativo (...) Nós mudamos: de pedintes passamos a atores (...)”.

\section{Espírito Santo:}

“(...) com a municipalização, nós mandamos relatórios para todos os Secretários Municipais de Saúde com as informações sobre nossos funcionários e cargo efetivo. Os Conselhos Regionais solicitam, o Sindicato, que quer saber quantas pessoas, qual a formação, a Procuradoria Jurídica, todos os processos judiciais vão lá para se levantar endereços, a Auditoria do Estado (...). O recadastramento foi feito no local, nós dividimos em equipe, cada equipe foi a um local (...) teve aquele envolvimento total do pessoal das regionais que fizeram a coleta e tudo. Só não conseguimos pegar as pessoas que ainda estão de fora porque estão licenciadas ou afastadas de suas unidades por qualquer outro motivo. Todas as etapas sempre foram tranqüi- 
Avaliação de Processo na Implementação de Políticas Públicas: a Implantação do...

las na digitação, na ficha, a emissão de relatórios (...) deu um ou outro problema, um diretor (...), mas na maioria houve um acompanhamento muito bom em todas as etapas (...)".

\section{Montes Claros:}

“(...) na minha opinião, o sistema foi de muita importância, inclusive me surpreendeu. Como eu falei, no início eu não gostei do sistema. Eu falei: isso não vai resolver o problema aqui para nós. Isso pode funcionar muito bem lá. Mas aqui não vai funcionar, não. Só que hoje eu vejo que ele superou a minha expectativa (...). A gente tem interesse porque hoje a informática está muito desenvolvida e se a gente não estiver assim com a informatização que está aí, hoje, a gente não avança (...)".

\section{O que Mostra o Estudo de Casos}

A avaliação da implantação de um sistema de informação sobre recursos humanos em saúde, utilizando dados quantitativos e qualitativos, processados via tecnologia computacional (SIG-RHS) e a utilização das informações para gestão de processos de RH e do sistema de saúde em nível local demonstram evidências positivas, pela análise dos indicadores de desempenho, eficácia e impacto observados. Os processos nucleares de implantação do SIG-RHS que respondem pelos níveis de desempenho estão relacionados com a operacionalização do sistema pela área de $\mathrm{RH}$ e a qualidade da avaliação e monitoramento.

- O desempenho observado nos diversos locais estudados não foi condicionado pela decisão da implantação a partir de altas instâncias de gestão (Secretário de Saúde). Os processos foram capitaneados pela área de RH com suporte da área de informática ou somente pela área de RH. A profissionalização da gestão de RH representou um elemento decisivo para o desencadeamento do processo, na qualificação de sua condução e na utilização das informações geradas para a gestão.

O processo de avaliação e acompanhamento da implantação mostrou-se capaz de detectar distorções e validar os dados digitados. A qualidade dos processos de divulgação da implantação do SIG-RHS, embora tenha apresentado influência positiva na maioria dos locais estudados, não mostrou comportamento linear. 
- O investimento e o apoio logístico dispensado para a implantação do SIGRHS demonstraram influência positiva para implantação do SIG-RHS, particularmente nas SMS. As capacidades institucionais prévias qualificaram o processo de implantação e possibilitaram uniformizar procedimentos em locais com quantitativo elevado de funcionários.

Apesar de uma tendência para melhor desempenho nas SMS, este entretanto não se mostrou tão diferente daqueles observados nas SES. É importante ressaltar que as finalidades da implantação do SIG-RHS foram de ordens diferentes nas SMS e nas SES e contribuíram para o alcance dos objetivos delineados para a utilização da informação.

A manutenção de procedimentos considerados inovadores em processos de gestão na administração pública está condicionada à institucionalização desses processos. A descontinuidade de gestão pode impedir a institucionalização, independentemente de capacidades institucionais prévias e do investimento dispensado ao processo.

A necessidade de informações sistematizadas para a gestão de processos de RH e do sistema de saúde superou condições de baixo desempenho e eficácia do processo de implantação.

Ao analisarmos o desempenho dos locais estudados, observamos que, entre os que apresentaram alto desempenho, encontram-se três SMS e uma SES; e entre os de médio desempenho, situam-se uma SMS e duas SES. A escolha dos casos não foi uniforme em relação ao quantitativo de SMS e SES.

Tal fato não invalida as indicações dos resultados, pois obviamente as similaridades ou divergências encontradas nos casos em implantação do SIG-RHS analisada não estão relacionadas unicamente com as instâncias de governo gestoras e seus atributos específicos. As SMS apresentavam intenso processo de reestruturação administrativa, desencadeado a partir da reforma em curso. A autonomia de gestão dos sistemas municipais de saúde condicionou processos para aprimoramento e otimização de recursos não só financeiros, mas principalmente humanos.

A necessidade de redimensionamento da rede de serviços de saúde, a partir da incorporação de prestadores estaduais e federais, ampliou o universo de atuação. Expôs deficiências ou excessos de recursos humanos não quantificáveis ou qualificáveis pelas fontes de dados disponíveis nos sistemas locais administrativos. Assim, podemos afirmar que nas SMS essas demandas envolviam diretamente os processos de planejamento e gestão.

Os objetivos para implantação do sistema de informação nas SES foram 
direcionados pela necessidade primeira de um diagnóstico da situação frente às distorções administrativas de diversificadas ordens acumuladas por sucessivas gestões. A descaracterização dos planos de cargos e salários proporcionada por adição de vantagens salariais, jornadas de trabalho especiais ou individualmente, aferidos judicialmente, entre outras coisas, determinaram motivações específicas das SES, o que incluía a elaboração de um novo PCCS.

O processo de reforma do sistema de saúde, por um lado, e a introdução da tecnologia da informática nas organizações, por outro, espelham a via comum demandante do processo de implantação do SIG-RHS.

\section{Referências Bibliográficas}

ARRETCHE, M. T. S. Tendências no estudo da avaliação. In: RICO, E. M. (Org.). Avaliação das Políticas Sociais: uma questão em debate. São Paulo: Cortez, 1999.

CARVALHO, A. O. Tecnologias da informação na gestão da saúde. Revista de Administração Pública. Rio de Janeiro, v. 32, n. 2, p. 195-205, 1998. DAL POZ, M. R. Sistema de informação sobre recursos humanos como instrumento estratégico para alcançar eficiência e democratização na gestão local de saúde. Educación Médica y Salud. v. 29, n. 2, p. 164-173, 1995. DENIS, J. L.; CHAMPAGNE, F. Análise da implantação. In: HARTZ, Z. M. A. (Org.). Avaliação em saúde: dos modelos conceituais à prática na análise da implantação de programas. Rio de Janeiro: Fiocruz, 1997, p. 4988.

FARIA, R. M. Avaliação de programas sociais - evolução e tendências. In: RICO, E. M. Avaliação das políticas sociais: uma questão em debate. São Paulo. Cortez, 1999.

HARTZ, Z. M. A. (Org.). Avaliação em saúde: dos modelos conceituais à prática na análise da implantação de programas. Rio de Janeiro: Fiocruz, 1997.

NÚCLEO DE ESTUDOS EM POLÍTICAS PÚBLICAS. Análise qualitativa dos programas inovadores do comunidade solidária. Relatório Final, 1. Campinas: NEPP/UNICAMP, 1999. Documento Metodológico.

NÚCLEO DE ESTUDOS EM POLÍTICAS PÚBLICAS. Análise qualitativa dos programas inovadores do comunidade solidária. Relatório Final, 2. Campinas: NEPP/UNICAMP, 1999. 
PEREZ, J. R. P. Avaliação do processo de implementação: algumas questões metodológicas. In: RICO, E. M. (Org.). Avaliação das políticas sociais: uma questão em debate. São Paulo: Cortez, 1999.

PIERANTONI, C. R. Reformas da Saúde e recursos humanos: novos desafios $\mathrm{x}$ velhos problemas. Um estudo sobre recursos humanos e as reformas recentes da política nacional de saúde. 2000. Tese (Doutorado em Saúde Coletiva) - Instituto de Medicina Social, Universidade do Estado do Rio de Janeiro, Rio de Janeiro.

RICO, E. M. (Org.). Avaliação das políticas sociais: uma questão em debate. São Paulo: Cortez, 1999.

SIG-RHS. Manual do gestor: versão 2.20. Rio de Janeiro: IMS/UERJ, 1996. Mimeografado.

VIANA, A. L. Abordagens metodológicas em políticas públicas. Revista de Administração Pública. Rio de Janeiro, v. 30, n. 2, p. 5-43, mar./abr. 1996. VIANA, A. L. As políticas sociais e as políticas de saúde no contexto da globalização. In: GERSCHMAN, S.; WERNECK VIANNA, M. L. (Org.). A miragem da pós-modernidade. Rio de Janeiro: Fiocruz, 1997.

VIANA, A. L. Enfoques metodológicos em políticas públicas: novos referenciais para estudos sobre políticas sociais. In: CANESQUI, A. M. Ciências Sociais e Saúde. São Paulo: Hucitec, 1997.

VIANA, A. L.; DAL POZ, M. R.(Coord.) Reforma em Saúde no Brasil: Programa de Saúde da Família. Informe Final. Rio de Janeiro: IMS/UERJ, 1998b (Série Estudos em Saúde Coletiva, 166).

VIANA. A. L.; DAL POZ, M. R. A reforma da saúde no Brasil e o Programa de Saúde da Família. Physis - Revista de Saúde Coletiva. Rio de Janeiro, v. 8, n. 2, p. 11-48, 1998a.

YIN, R. K. Case study research: design and methods. Newbury Park, CA: Sage Publications, 1989.

\section{NOTAS:}

1 Médica, doutora em Saúde Coletiva. Professora adjunta do Departamento de Planejamento e Administração em Saúde do IMS/UERJ. Coordenadora do Mestrado Profissional em Administração de Saúde e do Curso de Especialização em Administração Hospitalar do IMS/UERJ. Consultora da Estação de Trabalho IMS/UERJ da Rede Observatório de Recursos Humanos em Saúde OPAS/OMS/MS.

2 Economista, doutora em Políticas Sociais (UNICAMP). Professora adjunta do Departamento de Medicina Preventiva da Faculdade de Medicina da Universidade de São Paulo. 
3 Sugerimos consultar Dal Poz (1995).

4 Viana (1997) enfatiza a necessidade de utilização de um conceito preciso de políticas públicas, pois este delimita o espaço de atuação do objeto investigado. Aponta ainda as dificuldades para esta conceituação, referentes à pluralidade de modelos conceituais existentes e ao fato de contextualizar o espaço da política social, dentre os quais as políticas públicas. A autora conceitua política pública a partir dos referenciais de Lemiex (1994 apud Viana, 1997), como tentativas de regular situações que apresentam problemas públicos emergentes em uma coletividade ou entre coletividades, independentemente das áreas de atuação ou interferência.

5 Sugerimos consultar Rico (1999), Hartz (1997), Viana (1996, 1997, 1998), entre outros autores e publicações da área.

6 O Estado do Rio de Janeiro não conseguiu realizar o levantamento completo do contigente de servidores, em função de mudanças na conjuntura política que modificaram as relações com a instância federal do INAMPS. Posteriormente, com o desenvolvimento do software, também não utilizou este sistema de informações, excetuando-se demandas espontâneas, como o Hospital dos Servidores do Estado e, mais recentemente (1999), do Hospital do Andaraí (MS).

7 A metodologia de avaliação de processo foi desenhada a partir do desenvolvimento metodológico do projeto Análise Qualitativa dos Programas Inovadores do Comunidade Solidária (NEPP, 1999).

$8 \mathrm{O}$ estudo proposto envolve a avaliação de um projeto com a participação de diversos atores: a pesquisadora, a coordenação geral do projeto, a equipe técnica do DPAS/IMS/UERJ e os integrantes das equipes locais responsáveis pela implementação e operacionalização do sistema (gestores, técnicos de recursos humanos cadastrados e outros usuários em potencial das informações).

9 Equipe do Departamento de Planejamento e Administração em Saúde do IMS/UERJ.

10 Pode-se agregar o conceito de capital social ao de eficiência social: um programa é socialmente eficiente quando agrega capital social para se implantar, traduzido pela participação social, rede social de apoio e grupos de interesse mobilizados (por exemplo, sociedades profissionais).

11 O tempo decorrido entre a coleta de dados e a emissão do primeiro relatório comporta uma etapa importante relacionada à digitação dos dados. O distanciamento entre a coleta de dados e a emissão de relatórios pode ter como conseqüência informações não confiáveis relacionadas às movimentações, dispensas, aposentadorias etc., prejudicando a atualidade dos dados e a utilização do sistema como instrumento para planejamento e gestão.

$12 \mathrm{O}$ questionário foi elaborado a partir das experiências acumuladas pela equipe do DPAS/IMS/ UERJ, com a implantação e utilização do sistema nos diferentes locais, buscando-se identificar questões críticas e atores envolvidos no processo. Esta etapa contou com a participação de Anna Maria Campos (professora adjunta do DPAS/IMS/UERJ).

13 Qualificação é aqui relacionada a processos de formação, especialmente para categorias de nível médio da área da saúde.

14 Os processos de educação continuada estão definidos de forma mais ampla, englobando treinamentos e capacitações específicas para nível superior, médio e elementar. 
Evaluation of Public Policy Implementation: Human Resources Information and Management Systems in the Context of Health Sector Reforms in Brazil

The need to establish management tools for human resources in health spawned the development and implementation of the Brazilian Human Resources Information and Management System in Health (SIG-RHS). The article evaluates the implementation of this system in Health Departments in selected States and Municipalities and presents the process (implementation) evaluation methodology, describing the stages and construction of indicators, in addition to discussing the results. It goes on to identify the limits and possibilities for using the system as a human resources planning and management tool in local health systems.

Keywords: Human resources in public health; health policy; evaluation of public policies; information systems.

Recebido em: 08/05/2002.

Aprovado em: 15/12/2002. 